\title{
EL MODERNISMO DESDE LA PERIFERIA
}

\author{
Carlos Blanco Aguinaga \\ University of California, San Diego
}

Doy en estas páginas por supuesto: (1) que las representaciones de todo tipo que definen la modernidad empiezan a ser reconocibles en los países centro del capitalismo occidental desde antes de la primera guerra mundial y de la revolución bolchevique; (2) que antes del desarrollo de las sociedades socialistas por ahora desaparecidas, varios y muy diversos países europeos han de considerarse periféricos respecto a ese centro (no sólo Rumanía, por ejemplo, sino, incluso, Italia, o la Rusia de los zares, o Suecia); (3) que tanto Latinoamérica como España, con diferencias matizadas no sólo entre las dos sino en el interior de Latinoamérica, han sido por mucho tiempo, y siguen siendo, sociedades y terrenos de lucha cultural periféricos con respecto al centro capitalista hegemónico.

Ahora bien, importa para entendernos no olvidar que la "periferia" del mundo capitalista no es algo que se encuentra fuera del círculo, del otro lado de sus límites, sino que es su misma circunferencia. Es decir, los periféricos somos parte del círculo pero no estamos en su centro; somos, por así decirlo, "la frontera" entre el círculo y todo lo demás.

Pero la metáfora no puede entenderse en forma absoluta; es decir, no puede entenderse en nuestro tiempo como si más allá de esa "frontera" hubiese otras sociedades, ya que, de hecho, ninguna sociedad está hoy completamente fuera del círculo y, en términos económicos, por ejemplo, el más remoto lugar del mundo está desde hace más de un siglo conectado colonial o neocolonialmente con la metrópoli por necesidades de producción y de mercado, actuales o en potencia. Es decir, que la circunferencia económica y política del mundo moderno no es esa línea delgadísima con que representamos lo que, de hecho, es la idea del círculo, o sea, una abstracción, sino que se ensancha hasta donde ya no hay más países o zonas, a veces gradualmente (México, Noruega, Perú, Portugal, Guatemala), otras con saltos (España, México, Colombia $=/=$ Somalia) .

En este modelo el "mundo hispánico" ocupa un lugar privilegiado para entender no sólo las relaciones económicas y políticas entre centro y periferia, sino las relaciones culturales, ya que si bien a partir del siglo XVI España incorporó a América, en calidad de subordinada, a lo que entonces era el interior del círculo hegemónico europeo, ya desde las independencias americanas, y con el auge de nuevos imperios, tanto Latinoamérica como España se ven relegadas a la situación periférica que siguen ocupando. Esta experiencia de la inserción de la colonia en la estructura económica y cultural de la metrópoli, seguida por ciento cincuenta años de desplazamiento de las dos hacia la periferia, experiencia absolutamente única en la historia del colonialismo y neocolonialismo modernos, es la que nos sitúa en una posición de privilegio para entender el problema que va a ocuparnos. 
Culturalmente, por ejemplo, ello significa que si, en la plenitud del imperio español, en España y en América se leían autores europeos —clásicos y contemporáneos- y en Europa autores españoles a la vez que, por ejemplo, las obras de un Juan Ruiz de Alarcón se representaban en España, ya desde las independencias latinoamericanas y desde los inicios de los imperios modernos (apogeo del Imperio británico en su fase victoriana; creciente presencia cultural francesa; inicios de la presencia de USA), España vive en un mundo cultural doble, el suyo propio y el importado, en tanto que Latinoamérica vive su mundo cultural como - por lo menos- triple: lo prehispánico, lo español (con lo que trae consigo de europeo) y lo europeoyanqui moderno, en tanto que - por el contrario - la Europa del capitalismo avanzado y USA desarrollan su hegemonía cultural sin presencia significativa española ni latinoamericana alguna.

Dos de nuestros grandes escritores podrían representar esta situación: en América, el Martí conocedor de varias lenguas y culturas que propone que "nuestras repúblicas" han de injertarse en "el mundo", pero que "el tronco ha de ser el de nuestras repúblicas" '; en España, el Unamuno catedrático de griego y latín, conocedor también de varias lenguas y literaturas europeas ( $y$, cosa bastante rara en la España de entonces, conocedor de algunas literaturas latinoamericanas) que en 1895, en pleno debate sobre el concepto de "casticismo", a la vez que polemiza con el Poema del Cid, Calderón, etc., remite indirectamente a Hegel y propone que es cosa buena que la cultura "europea" invada España ${ }^{2}$.

Martí y Unamuno son ejemplares porque, al igual que cualquier intelectual español 0 latinoamericano medianamente serio de hoy, sin dejar de pisar su propio terreno, se mueven auténticamente en situaciones que ahora, tal vez, llamaríamos pluriculturales, en tanto que la cultura hegemónica sigue básicamente desconociendo sus obras; es decir, en tanto que esa cultura sigue sin considerarles parte de un canon que pretende representar al mundo. Con las diferencias históricas y las graduaciones que he apuntado, esta situación es hoy característica de las relaciones entre todas las sociedades "fronterizas" y la metrópoli.

Creo, por tanto, que si bien Carlos Fuentes se equivocaba radicalmente hace veinticinco años cuando - al tratar de cuestiones económicas y políticas-escribía que ya no había centro en el mundo, que todos éramos ex-céntricos ${ }^{3}$, acertaba plenamente en cuanto a nuestros modos de vivir la cultura, ya que los más de nosotros vivimos en, por lo menos, dos centros culturales que, en nosotros, se cruzan y se nutren mutuamente. Somos culturalmente seres fronterizos y, por tanto, vivimos un variado lenguaje cultural. Tanto es así que a veces se diría que tenemos un lenguaje para andar por casa y otro(s) para salir (que es un entrar como de emigrantes) al mundo de la hegemonía.

Y no empleo el término "lenguaje" en forma exclusivamente metafórica ya que lo que aquí nos reune es, precisamente, la interpretación y valoración de una palabra, modernismo, que hasta hace poco significaba para nosotros dos cosas contemporáneas pero distintas: secundariamente, el movimiento religioso de pretensiones científicas, ambigüamente apoyado por Leon XIII y luego condenado por Pío X en 1907; y, centralmente, el movimiento literario encabezado por Rubén Darío que, según propuesta de Federico de Onís, se situaría entre 1886 y 1905 y que sería "la forma hispánica de la crisis universal de las letras y del espíritu que inicia hacia 1855 la disolución del siglo XIX y que se había de manifestar en el arte, la ciencia, etc..." 4 
Desde hace unos cuarenta años, sin embargo, la cultura hegemónica, especialmente en su vertiente anglo-americana, ha venido empleando el término modernismo en un sentido muy distinto de los de estas versiones nuestras del mismo y, ahora, casi seguramente como rebote de la difusión del término post-modernismo, ese otro concepto de modernismo ha sido adoptado -entre contradicciones y polémicas internas - por todas las vertientes de la cultura hegemónica.

Frente a este hecho, quienes vivimos en la periferia podemos posicionarnos de dos maneras: insistiendo en nuestros significados de modernismo (especialmente según la versión de Federico de Onís), o aceptando como borreguitos el nuevo significado. Si lo primero, se nos relegará con una simple nota al pie al último rincón de la frontera mientras el resto del mundo sigue su marcha ${ }^{5}$; si lo segundo, podremos hablar con quienes estudian a Eliot, o a Pound, o a Kafka, pero nos resultará difícil (si no imposible) hablar ya coherentemente entre nosotros acerca de Rubén Darío, o de Julián del Casal, o de Valle Inclán.

Claro que siempre cabe la posibilidad de hablar en casa de una manera y fuera de casa de otra. Pero esto puede llevar a problematizar nuestro ser de fronterizos en el peor de los sentidos: seres sin remedio escindidos. Exactamente lo contrario del sano ideal que proponía Martí cuando hablaba de un tronco injerto en la cultura "universal"; lo contrario también de la vital contradicción del Unamuno que, alternativamente, y entre luchonas contradicciones, proponía unas veces la "europeización" de España y otras su "africanización".

¿Cómo evitar la escisión, un tal no saber qué terreno pisamos? Quizá la solución se encuentre en la idea que —según entiendo-ha dado origen a esta reunión. Podemos decidir que no vale la pena discutir sobre palabras y, puesto que el nuevo sentido de modernismo parece haberse ya impuesto en la cultura hegemónica que todo lo invade, lo que debe importarnos es descubrir y explicar nuestra participación en ese modernismo puesto que - $\mathrm{y}$ valga un sólo ejemplo para empezar- Picasso, sin quien, según algunos, una vertiente clave del modernismo sería inconcebible, era, a fin de cuentas, un periférico.

Si a partir de aquí repasamos una versión cualquiera del canon "modernista" (incluso la más restrictiva, que sería la que se ocupa sólo del llamado "high modernism") nos encontramos no sólo con - por ejemplo- T.S Eliot, Pound y Gertrude Stein, sino con Joyce y Kafka, periférico tal vez el primero de éstos dos por su simple ser irlandés y periférico el segundo por ser - a más de judío- esa cosa tan extraña que significaba a principios de siglo haber nacido en Praga y hablar y escribir en, por lo menos dos lenguas, una hegemónica y la otra para andar por casa. Crece entonces en nosotros la sospecha, confirmada en algunos de los estudios más sensatos sobre el asunto, de que el llamado modernismo tal vez deba en cierta medida su existencia a agentes culturales legal o ilegalmente emigrados desde la frontera hacia el interior del círculo, incluso hasta su mismísimo centro. Y cuando añadimos a la lista algunos nombres de cuyo modernismo nosotros no dudaríamos (por ejemplo, entre otros, Stravinski, ruso; Apollinaire, polaco-italiano; Chirico, italiano; o Tzara, rumano), parece ya indudable que, como toda empresa colonial, la de quienes hablan hoy de modernismo desde la metrópoli se sustenta en gran medida en la apropiación de la producción, cultural en este caso, de lo ajeno.

De hecho, en manos de estudiosos inteligentes, culturalmente abiertos y no excesivamente colonialistas, el ahora llamado modernismo se concibe como un amplio y transformador movimiento que, centralmente situado en la Metrópoli, nace — según indicaba de 
Onís - "de la crisis universal de las letras y del espíritu que inicia hacia 1855 la disolución del siglo XIX" y se ahonda y desarrolla impulsado en gran medida por pensadores, escritores, músicos y artistas plásticos periféricos. Remito, como único ejemplo, a la excelente colección de ensayos titulada Modernism, 1890-1930, editada por Malcolm Bradbury y James McFarlane en $1978^{\circ}$. Junto a Baudelaire y Rimbaud, por ejemplo, ocupan ahí su justo sitio en los orígenes del modernismo Ibsen y Strindberg y —entre muchos otros - juegan papeles centrales en su desarrollo los ineludibles Picasso, Tzara o Stravinski, periféricos todos que trabajaron en el centro mismo de la Metrópoli. Se encuentran, incluso, las que a nosotros no pueden sino parecernos inevitables referencias a Ortega (a propósito, naturalmente, de lo de "la deshumanización del arte") y, aunque muy de pasada, se mencionan también a García Lorca y a Borges (pero cuando se menciona la revista "Nord-Sud" no se dice nada de Huidobro).

Podríamos, por tanto, aceptar sin muchos aspavientos esta versión del modernismo, cuya amplitud misma nos permitiría añadir a la ya larga nómina de sus principales actores no pocos nombres de los nuestros, probablemente desconocidos para la mayoría de los especialistas anglosajones.

Así, dejando tal vez de lado el hecho de que en el momento más difícil de clasificar para quienes en la cultura hegemónica se ocupan del asunto, es decir, en el ocaso de ese momento que todavía algunos llaman "simbolista" (cuyo momento corresponde al periodo acotado por de Onís), Azorín y Unamuno - sin ir más lejos- planteaban ya en La voluntad (1902) y en Niebla (1907-1914) la cuestión del sujeto "descentrado" y "desrealizaban" la novela, recordaríamos que, en pintura por ejemplo, los nuestros serían nada menos que - entre otros, y además de Picasso- Gris, Miró, Dalí, Orozco, Rivera y Siqueiros. Podría, tal vez, disputársenos la inclusión de los tres mexicanos: porque no pintaron lo definitivo de su obra en París; porque es central en ellos el elemento socio-histórico que los más de los especialistas en modernismo pasan por alto; y porque pintaron murales (de modo que — salvo peregrinajes a cuatro o cinco edificios yanquis - hay que viajar hasta "la frontera" misma para ver una obra que, además, no puede venderse). Creo, sin embargo, que podrían alegarse los casos y que, dados otros acuerdos acerca del significado del concepto hegemónico de modernismo, no resultaría excesivamente difícil llegar a un acuerdo sobre la inclusión en la nómina de Orozco, Rivera y Siqueiros.

Tampoco en el cine habría problemas: bastaría con nombrar a Buñuel. Y si en música tal vez inician el modernismo Debussy y Ravel (quienes tantas veces se apropian, sin cambio alguno, ritmos y melodías de la frontera española del imperio), ¿por qué no Albéniz? Y si Satie, ¿por qué no Mompou? Y si Bartok, ¿por qué no Falla o Revueltas?

Más espectacular, si cabe, sería nuestra contribución al modernismo literario. Para empezar, junto al también periférico Marinetti, pero un poco por delante del italiano, estaría, por ejemplo, Ramón Gómez de la Serna. Luego vendrían Huidobro y el Vallejo que escribe Trilce en Perú. Y, poco después, ya en tiempos de los "esperpentos" de Valle Inclán, toda esa pléyade de poetas nacidos en América y España entre —más o menos- 1895 y 1905. ¿Cómo es posible - nos preguntamos a veces - que se haga la historia del ahora llamado modernismo sin la menor referencia a éstos y otros escritores? Recordemos brevemente, y como simples ejemplos, dos o tres textos característicos de sólo dos de nuestros poetas, Huidobro y García Lorca. 
Se me ocurre, por ejemplo, no olvidarme del bonito poema de Huidobro titulado "Torre Eiffel", publicado en francés en el libro Tour Eiffel, en 1917. Se trata, desde luego, de un poema relativamente "menor" del chileno. Además, el "tema" de la Torre Eiffel, cuya estación de Telegrafía sin hilos (sistema, dicho sea de paso, inventado por Marconi, italiano) comunicaba real y míticamente los más apartados lugares del mundo, había sido ya tratado brillantemente por Blaise Cendrars, incluso con algunas de las imágenes y conceptos que poco después utilizará Huidobro. Me interesa, sin embargo, recordar este poema de Huidobro, porque sitúa claramente el quehacer del "creacionista" en el ámbito del "simultaneísmo" que -originalmente teorizado y puesto en práctica para la poesía por el citado Cendrars - no sólo remite a procedimientos pictóricos del cubismo, sino que, temáticamente, propone nada menos que la visión de la convivencia simultánea de los más dispares lugares y sociedades del mundo, en lo que fue un notable y conflictivo intento no sólo de "acaparación" imperial, sino de apertura metropolitana hacia modos de vida y de producción artística periféricos.

Respondiendo, tal vez intuitivamente, a este aspecto de la modernidad, el periférico Huidobro no dudó en instalarse en París, en dirigir con Reverdy la revista Nord-Sud y en escribir, a su manera, los mitos de la modernidad hegemónica. Con una peculiaridad: que escribía y publicaba en francés y en castellano. Es decir, que mientras se sumergía en el quehacer artístico de la metrópoli, pretendía — como quien dice "simultáneamente"- llevar la modernidad hacia la cultura de su origen. Bilingüismo y biculturalismo activos inconcebibles no sólo en Eliot o en Faulkner, por ejemplo, sino en el mismísimo pretencioso fascista de impostada cultura mediterránea y estudiante de las lenguas romances que fue Pound. Ante lo cual, de poco me sirve a mi que pueda decirse que lo "original" del poema "Torre Eiffel" no está en Huidobro, sino en Cendrars porque, que yo sepa, aunque en los movimientos artísticos siempre hay figuras mayores y menores, al tratar de comprender esos movimientos no sólo nos ocupamos de las figuras "mayores". Si no, ¿por qué y para qué, al estudiar el cubismo, nos hacen falta Braque o Gris junto a Picasso?

Por lo demás, creo que difícilmente encontraremos en la literatura hegemónica un texto que proponga mejor la autonomía del poema (tema clave de las vanguardias, sin las cuales no habría modernismo ), su independencia incluso, que este momento de Manifestes (París,1925) del mismo Huidobro.

Os diré - escribe el chileno-lo que entiendo por un poema creado. Es un poema en el que cada parte constitutiva y todo el conjunto presentan un hecho nuevo independiente del mundo externo, desligado de toda realidad que él mismo, pues toma su lugar en el mundo como un fenómeno particular, aparte y diferente de los otros fenómenos. Es bello en sí y no admite término de comparación. No puede concebirse en otra parte que en el libro. No tiene nada de semejante con el mundo exterior; hace real lo que no existe, es decir se hace él mismo realidad. Un poema es un poema, tal como una naranja es una naranja y no una manzana. Encontraréis ahí lo que nunca habéis visto en otra parte: el poema. Una creación del hombre.

Cierto que para explicar esta idea de la independencia del objeto artístico, tan característica de las vanguardias, idea que — sin duda - venía gestándose desde, por lo menos, 
Baudelaire (si es que no desde T. Gautier), podemos recurrir a muchos otros textos equivalentes sobre literatura, pintura, música; etc.. Y cada lector o crítico, según sus conocimientos y sus presupuestos culturales, escogerá entre cientos de textos aquellos que le sean más accesibles, 0 más útiles, o más acordes con su tendenciosidad. Yo, desde luego, cuando intento explicarme 0 explicar algunas de las direcciones, tan contradictorias a veces, de aquel prodigioso momento cultural que podemos situar entre 1907 y 1925 o 1930, acudo, como todos, a los escritos de las vanguardias de muy diversos países; pero como pienso y escribo en español, y como sé que el pasaje citado de Huidobro, aunque relativamente tardío (por comparación con lo escrito por Apollinaire en 1913 sobre el cubismo, por ejemplo) es una de las exposiciones más brillantes de aquella idea de la vanguardia (y lo sé porque conozco las otras exposiciones) no pienso excluir al chileno de mi canon.

En cuanto a García Lorca, tranquila y gozosamente instalado en su propia y única lengua, me permito dudar que en la poesía hegemónica del llamado modernismo pueda encontrarse un texto que con mayor profundidad de visión y riqueza de lenguaje que Poeta en Nueva York represente no sólo la alienación de la vida urbana moderna —una de las tantas características, dicen, del modernismo - , sino su relación con la periferia. Y no me refiero sólo a la presencia en el libro de los oprimidos y explotados negros norteamericanos, una presencia que, en aquel entonces, sólo se encontraba en la metrópoli en Langston Hughes y en algunos otros de la "Harlem Renaissance" 7 sino también al hecho - yo diría que, en el fondo, nada sorprendente - de que haya sido un poeta andaluz, un poeta inmerso en lo popular de sus provincias y maestro del tradicional y seguro octosílabo, un joven que antes de su viaje a USA no conocía más ciudad grande que la pobretona Madrid de aquel entonces —-que haya sido alguien tan periférico quien escribiera uno de los más apasionantes libros de la modernidad urbana, y no situando el problema en París, sino nada menos que en el Nueva York del crack de Wall Street que los más mitificaban (Cendrars y Huidobro en París, por ejemplo; Salinas y Alberti en Madrid).

Mérito añadido para que García Lorca pudiese entrar en el canon del modernismo, tal vez especialmente cuando limitado al llamado "high modernism", sería que Poeta en Nueva York no se presenta como texto "vanguardista", sino que, al igual que algunos de los varios textos de ese canon (el "Ulises", los "Cantos."..), utiliza, "superándolos", procedimientos técnicos puestos en circulación por diversas tendencias de la vanguardia ("imagism", simultaneísmo, surrealismo...), con lo que, como quien dice, los estabiliza e inscribe para siempre en el estilo de la madurez conflictiva de la modernidad ${ }^{8}$. En la crítica española se ha hablado desde siempre, con razón, del "eclecticismo" de los del 27. Una pena que no hayamos sabido que eso se llamaría un día "high modernism".

Pero hay más, si atendemos a la cronología y a los cambios que en su interior sufre nuestro siglo entre 1917 y 1930. Porque ni la modernidad ni el modernismo se acaban en 1922 (Ulises, The Waste Land) o en 1924 (Der Prozess), según se demuestra con recordar, simplemente, que los "Cantos" de Pound se publicaron como volumen en 1934. Y lo que hay de más es ese cambio radical de dirección del siglo que, fuera de la URSS y de Alemania, no se da hasta, más o menos, los años difíciles que van entre 1930 y 1936, cuando el arte más representativo de su tiempo rompe con el concepto de la vanguardia "estética" y pasa a querer representar una nueva vanguardia político-artística. Sin ese momento (del cual, dicho sea de 
paso, los teóricos del modernismo, y especialmente los del "high modernism" prefieren no hablar), momento que se inscribe en la historia como lucha contra el fascismo en el interior de la hegemonía y en partes de la periferia europea, no sólo no existiría la modernidad, sino que nosotros no seríamos quienes somos. Y en esos años, en el centro de aquella lucha social, política y cultural, ¿encontraremos entre los poetas - junto, por ejemplo, a Maiakovski o a Brecht- poeta mayor que César Vallejo?

Fácilmente, pues, podríamos aceptar el significado, relativamente nuevo para nosotros, que del término modernismo se propone desde la hegemonía, y colaborar, de paso, en la construcción de su verdadero canon. Seguirían ahí, supongo, Eliot, y Pound, y Stein, y Joyce, y Kafka, y Beckett, etc. Pero en el interior de las contradicciones y las luchas que, de hecho, marcan el siglo y, por tanto, la "modernidad", esos escritores compartirían su lugar con Picasso, Buñuel, Huidobro, García Lorca, Orozco, Falla, Vallejo, Neruda, Alberti, etc. etc. Tendríamos, pues, no sólo mucho de lo cual sentirnos orgullosos por lo que a nuestra contribución de fronterizos al desarrollo de la cultura hegemónica se refiere, sino que haríamos que esa cultura entendiera que, en cuanto representación de un capitalismo imperialista en crisis, necesitó entre 1900 y 1939 extraer de la periferia gran parte de su mejor talento, no sólo en su sentido primero de dinero o riqueza, sino en su más vulgar sentido metafórico.

De hecho, ese canon pluricultural, que sería el nuestro, ya fue propuesto hace muchos años, implícita pero descaradamente, en la curiosa y casi genial novela de Max Aub, Jusep Torres Campalans, en cuyo capítulo tercero, titulado "Anales", aparecen juntas —por fecha de nacimiento, o de muerte, o de publicación de sus textos y exposición de su obra- las figuras culturales de muy diversos países que han contribuído a la expresión de la modernidad. Así, por ejemplo, el ficticio Torres Campalans nace en 1886, el mismo año —nos recuerda Max Aubque Kokoschka y Diego Rivera, que es el año en que Rimbaud publica Las iluminaciones e Ibsen estrena Rosmersholm. Y lo que, según Max Aub, ocurre de importante en 1907 —por dar un sólo y arbitrario ejemplo más de una "cronología" que llega en estos "Anales" hasta 1914 es que en ese año, entre otras cosas que importan, nacen no sólo W.H. Auden y Christopher Fry, sino también Luis Felipe Vivanco y José Renau; publican textos importantes Carl Liebknecht, William James y Rubén Darío; Synge estrena The Playboy of the Western World, pinta Chagall sus primeras telas, Picasso termina Les Demoiselles d'Avignon, Kandiski exhibe en Frankfort, Apollinaire presenta Braque a Picasso, se filman las primeras películas de largo metraje, y Ravel escribe la Rapsodia española. En fin, que la visión que tiene Max Aub del modernismo es, o debería ser, toda una lección cultural.

Pero lo que ocurre, claro, es que, aunque podamos llevar a cabo en casa $-\mathrm{y}$ con gran distancia irónica - la "operación Max Aub", no tenemos la menor posibilidad de cambiar en el interior de la hegemonía el canon que nos excluye (Who is Max Aub?). Y ello por varias razones. La más general es perfectamente obvia: quienes controlan la economía mundial, el poder militar, las decisiones políticas que les importan, y la casi totalidad de los sistemas de comunicación del mundo, no tienen por qué atender a las llamadas de atención de una "frontera" que consideran ajena al círculo, excepto cuando — por lo que sea—esas llamadas le interesan.

Pero hay también razones específicas. La primera, a la que he aludido sólo implícitamente, es que reina una gran confusión entre los teóricos de la cultura hegemónica 
acerca de lo que sea o deje de ser el modernismo. Es de suponer $-\mathrm{y}$ me temo que no hay más remedio que volver a los significados de las palabras-que todos saben que en cualquiera de las lenguas que se manejan en la hegemonía "moderno" significa "actual", algo que está ocurriendo o que ha ocurrido hace "poco tiempo", y que "modernista" significa, simplemente, quien tiene afición "a lo moderno", por oposición a quien prefiere lo anterior. Pero claro que, entendido así el significado de "modernismo" según cualquier diccionario castellano, inglés, francés, italiano o alemán, resulta muy difícil separar - por ejemplo - a Cendrars de Pound ya que los dos están en plenitud de facultades prácticamente al mismo tiempo, aunque Cendrars venga de algo más lejos.

Doy estos dos nombres porque - según he indicado- la confusión principal de los "teóricos" del modernismo parece centrarse en el problema que plantean las "vanguardias", cuya posición de avanzada todos-inevitablemente- reconocen, pero que la tendencia dominante en la construcción del canon, especialmente la de quienes reducen el modernismo al llamado "high modernism", no considera "modernistas", ya que para esta tendencia - y ello es en gran medida cierto ${ }^{9}$ - las "vanguardias" son destructoras, en tanto que los modernistas propiamente dichos (que serían Pound, Eliot, Joyce, Kafka, Virginia Woolf, y muy pocos más), aunque parten, según se dice, de la misma visión negativa del mundo y utilizan a menudo procedimientos técnicos descubiertos por los "vanguardistas", pretenden de diversas maneras reconstruir equilibrios clásicos. Así, de un sólo golpe dizque "teórico", quedan excluídos del canon Gómez de la Serna, Picasso, Marinetti, Apollinaire, T.E. Hulme, Tzara, Cendrars, Breton, etc., etc., y no-claro está- por periféricos, sino por vanguardistas.

La segunda parte de la operación exclusivista de los teóricos de la tendencia dominante en el interior de la hegemonía es igual de sencilla: reducen el modernismo a la literatura, con lo cual, por si no bastara con lo logrado por el otro flanco, desaparecen Picasso, Gris, Dalí, Orozco, Rivera, Buñuel, etc., junto con Chirico, los constructivistas rusos, Kandinski, etc. Porque, claro, la pintura, la música y el cine las pueden ver y oir todos, lo que provocaría preguntas, en tanto que la literatura, aunque se vean sus letras y se oigan sus sonidos, hay que saber lo que dice. Y nuestras literaturas se escriben en una lengua que hay que traducir porque hace siglos que se encuentra en la periferia. Es fácil, así, "silenciar" a César Vallejo, por ejemplo.

El remate, rara vez explícito, de esta operación doble consiste en pasar completamente por alto ese momento crucial de nuestro siglo que, tras la fundación de la URSS, en pleno auge del marxismo en Alemania, y con la organización internacional de la lucha contra el fascismo produce el ya mencionado viraje radical en el arte moderno. Al excluir ese momento-cuya mayor vitalidad dura de, digamos, 1920 a 1939 - ya no sólo se excluyen del modernismo obras pictóricas como el "Guernica" e importantes textos literarios de varias zonas de la periferia (como la literatura de la "negritud", por ejemplo), sino incluso autores metropolitanos tan claves para una verdadera comprensión de la modernidad como pueden ser —entre muchísimos otros- los Spender, Brecht, Auden, Heinrich Mann, Caudwell o Eluard de esos años.

Llegamos así a lo que tal vez sea el meollo del asunto. Que la cultura hegemónica se apropia y excluye lo que le conviene de la periferia, eso es evidente; pero también deberíamos tener claro que, en su interior mismo, esa cultura hegemónica funciona por exclusión de lo que podría cuestionarla. Parece una vulgaridad, es una perogrullada, pero importa repetirlo por enésima vez y, además, en términos que ya no se usan: la oposición metrópoli-periferia es parte inseparable de la lucha de clases en el interior de la metrópoli. 
Así entendida desde nuestro punto de vista periférico y de clase, la pseudo-teórica operación "modernista" no puede sino parecernos absurda en su descarado imperialismo. Pero, ¿no es una operación perfectamente lógica desde el punto de vista de quienes, instalados antes en el imperialismo clásico, disfrutan ahora del "Nuevo Orden Mundial"? Y, dada la fuerza material de ese imperialismo, ¿qué posibilidades de éxito tendría una "operación Max Aub"? Además, aunque pudiésemos lanzar con éxito tal operación, ¿qué ganaríamos con ello? No creo que — “en última instancia”, según diría Engels - se juegue ahí el futuro de nuestras culturas fronterizas.

Tenemos que entender nuestra relación con la metrópoli: es cuestión de salud, individual y colectiva. Y en esa relación sigue siendo importante educar a los nuestros tanto en el conocimiento de la relación misma como en el pluriculturalismo que nos característica, en ese estar nuestro "tronco injerto en el mundo", que es lo que tenemos de más valioso. ¿Que los centros hegemónicos no se dan por enterados? Allá ellos; porque, la verdad, a estas alturas del siglo XX y con todo lo que se avecina, la cuestión me parece de poca importancia.

\section{Colofón}

Quizá importe decir que estas páginas responden a la convicción de que importa mucho para la sobrevivencia de los individuos y de los colectivos el tener una idea lo más realista posible de cómo (y dónde, y por qué) están situados en el mundo.

Doy también en ellas por supuesto que la situación histórica de un individuo o de un colectivo (clase, etnia, género sexual, cultura "nacional"...) no depende sólo de haber nacido a ella, ya que, en cualquier momento en que se haga el corte sincrónico, esta situación se revela como construcción histórica resultado de las relaciones dialécticas con "otros".

De ahí, quizá, la importancia de preguntarse algunas cosas acerca del llamado "modernismo" en la cultura hegemónica.

\section{Notas}

1. Nuestra América.

2. En torno al casticismo; passim.

3. Cf. Carlos Fuentes, La nueva novela latinoamericana, México D.F., Joaquín Mortiz, 1969. Passim.

4. Federico de Onís, Introducción a su Antología de la poesía española e hispanoamericana. Segunda edición, Nueva York (Las Américas), 1961; p. xv.

5. Cf., por ejemplo, la primera nota al pie de la primerísima página de la Introducción al libro de Astradur Eysteinsson, The Concept of Modernism, Cornell University Press, 1990.

The Harvester Press, Sussex/Humanities Press, New Jersey.

No menciono aquí el movimiento de la "negritud" en el Caribe o África porque ése se origina en la periferia.

Sobre esta característica del llamado "high modernism" cf., entre los más recientes, el ya citado libro de Eysteinsson. 
74 